\title{
O CRONISTA E A DAMA: FACETAS DA AIA INÊS DE CASTRO NA CRÔNICA DE FERNÃO LOPES
}

\author{
Mariana Bonat Trevisan ${ }^{10}$
}

RESUMO: Este artigo propõe uma análise sobre a representação que o cronista português Fernão Lopes (13801460) realiza acerca da personagem Inês de Castro (1325-1355) na Crônica de D. Pedro I. A crônica régia é uma obra de natureza laica, sendo que sua interpretação sobre fatos do passado difere bastante das crônicas produzidas por clérigos na Baixa Idade Média. Considerando as especificidades desta fonte e as características do texto lopeano, refletimos sobre a aia castelhana que se tornou a preferida do rei português Pedro Cru, relacionando alguns pontos referentes à noção que o cronista criou sobre esta mulher.

Palavras-chave: crônica régia, Portugal Medieval, representação feminina.

Ao iniciarmos um estudo sobre mulheres na Baixa Idade Média nos deparamos com uma questão fundamental: a maior parte dos documentos escritos que chegaram ao nosso tempo constituem-se de textos elaborados por homens. Neste sentido, é necessário ressaltar a reflexão que, o eminente estudioso do mundo medieval e da condição feminina neste período, Georges Duby, desenvolveu sobre tal problema. Em sua obra Eva e os Padres - Damas do século XII, o historiador aborda a temática referente às mulheres nobres do século XII, sobre as quais diversos padres e outros religiosos escreveram ou dedicaram obras. Duby enuncia em dado momento:

\footnotetext{
"Não tenho muita ilusão. O que escreveram sobre o cotidiano da existência feminina tampouco revela a verdade franca. Com efeito, são homens que se exprimem afogados em seus preconceitos de homem, (...). Assim, ainda desta vez, não hei de captar senão uma imagem das damas do século XII. Um reflexo vacilante, deformado." (DUBY, 2001, pp.7, 8).
}

O que se pode depreender desta passagem é o fato de que não podemos tomar textos elaborados sob a ótica masculina, como testemunhos informantes da real condição das mulheres no Medievo. Estes escritos nos expressam uma construção acerca do feminino, permeada pela subjetividade dos indivíduos que as elaboraram e pelas atitudes mentais correspondentes do meio e época em que estavam inseridos. Desta forma, a visão do homem que escreve sobre a mulher é sempre uma visão sobre a alteridade, já que ele, logicamente, não vivencia a experiência de ser mulher.

Duby trabalhou com fontes masculinas que se dirigiam às mulheres ou tratavam delas diretamente. Nosso objetivo aqui é tratar também de um discurso masculino, delimitando-o a uma personagem feminina específica. No entanto, nosso intuito não é trabalhar com a obra um clérigo do século XII, mas sim com a de um homem de um contexto posterior, já modificado e transformado após a crise iniciada no século XIII, que teve conseqüências dramáticas no século XIV ${ }^{11}$, um momento

10 Aluna do curso de Graduação em História da Universidade Federal do Paraná. É Bolsista do grupo PETHistória UFPR, no qual realiza a pesquisa individual "As aias Inês de Castro e Maria de Padilha nas crônicas de Pero Lopez de Ayala e Fernão Lopes", sob orientação da profa. Dra. Marcella Lopes Guimarães.

Referimo-nos ao período de crises que envolveu a economia e que gerou a grande fome, revoltas 
no qual se verificava uma importante modificação cultural: a laicização do saber. O homem de quem falamos é o português Fernão Lopes (1380-1460), provindo de origem não nobre, mas que conseguiu obter certo estudo ${ }^{12}$, destacou-se na corte portuguesa do rei D. Duarte (1433-1438) e ascendeu a cargos de confiança durante o reinado deste e de seu sucessor. Conforme Oliveira Marques, nosso autor foi nomeado em 1418 guardador-mor dos arquivos da Torre do Tombo, por volta da mesma época e antes de 1437 tornou-se tabelião geral. Seu progresso na corte veio a lhe render novos cargos: o de escrivão dos livros do infante D. Duarte, escrivão dos livros do rei D. João (1419), escrivão da puridade do infante D. Fernando (1421 até 1443, data da morte deste) e por fim, recebe o encargo de escrever as crônicas dos reis de Portugal até D. João I, por volta de 1434 (OLIVEIRA MARQUES, 1988: pp.93,94).

Fernão Lopes exerceu suas funções no reino português em um contexto pós-fundação da Dinastia de Avis, no qual o poder conquistado por D. João I (1385-1433), filho ilegítimo do rei D. Pedro I (1357-1367) - este o último representante da Dinastia de Borgonha em Portugal - já se encontrava consolidado. Tendo sido nobilitado por D. João e contratado de seus sucessores, pode-se antever o comprometimento que o cronista tinha com os membros da Casa de Avis e a responsabilidade, para um homem de saber como ele, de escrever as crônicas de tais governantes e seus antecessores. Fernão Lopes seguia um estilo de composição específico e próprio de sua época. Oliveira Marques nos afirma que as crônicas surgiram em Portugal por influência de modelos produzidos na França, Itália e, sobretudo, de sua vizinha Castela. O historiador postula que a crônica distingue-se de outras formas historiográficas pela maneira como nela se encadeavam os eventos descritos, a partir de um fio condutor narrativo e não já segundo uma ordem estritamente cronológica. Dirigiam-se a nobres ou clérigos, sendo também escrita por membros desses estratos sociais (OLIVEIRA MARQUES, 1988: p.18). No entanto, com Fernão Lopes já observamos uma modificação neste quesito, pois nosso cronista não provinha da nobreza nem do clero, mas era sim um indivíduo que conseguiu ascender na corte portuguesa. No século XIV, a crônica autóctone surge neste ambiente social e sendo já produzida em vernáculo, não mais em latim; refletia basicamente os interesses da nobreza, os atos políticos dos reis e a legitimação do reinado destes, sendo que neste âmbito os estratos mais populares não encontravam espaço. Conforme observaremos adiante, as crônicas de Fernão Lopes são intituladas sim a partir do reinado de monarcas portugueses e possuem certamente o compromisso de legitimar a dinastia que lhe pagava as tenças; no entanto, a grande maioria dos estudiosos de suas obras aponta para o importante lugar que o cronista concedeu em sua narrativa à "arraia miúda", principalmente quanto a sua participação ativa na crise dinástica de 1383-1385. Além disso, outra característica interessante é a personificação que o autor faz da cidade de Lisboa, palco primordial dos acontecimentos que darão origem a uma nova ordem no reino português.

sociais, foi arrasado pela Peste Negra, marcado por um declínio da produção cultural, entre outros pontos.

12 Consoante Saraiva, Fernão Lopes não teria sido um homem que necessariamente freqüentou a Universidade, mas deve ter obtido estudo em algum instituto de ensino anexo a catedrais ou a conventos. Pois não eram desconhecidos deste cronista historiadores latinos e filósofos gregos, nem literaturas mais contemporâneos, tais como a de Petrarca. (SARAIVA, 1950: 456). 
O cronista Fernão Lopes surge no século XV acompanhando o desenvolvimento deste tipo de composição em Portugal. Porém, Conforme Teresa Amado, a influência de outros cronistas ibéricos, notadamente a do castelhano Pero Lopez de Ayala (1332-1407), como fontes para a constituição de suas obras é extremamente importante. No entanto, ao analisar as obras lopeanas a autora afirma que elas não podem ser englobadas numa categoria geral de crônica dos séculos XIV e XV, pois encontram a especificidade do contexto português daquele período pós-criação da Casa Real de Avis. Desta forma, seus textos possuem características únicas que, porém, podem encontrar um isolamento menor se comparadas a crônicas nem sequer ibéricas, mas sim européias. A semelhança se dá, sobretudo, com textos de cronistas ingleses e italianos, pois utilizando o trabalho de Given-Wilson ${ }^{13}$, Teresa Amado constatou que a maioria dos cronistas ingleses do fim da Idade Média tinham a liberdade de escrever o que pensavam (AMADO, 2007: p.137). Ressaltando que uma das principais preocupações tanto de Fernão Lopes quanto dos demais cronistas laicos do período era a de dizer somente a verdade sobre os fatos que estavam narrando, observa-se aqui uma contradição de extrema importância para a compreensão da obra lopeana: o compromisso em dizer sempre a verdade, confrontado com a constatação de que todo o discurso é parcial por mais que se esforce em ser objetivo, revela-nos que o autor vai escrever o que julga ser a verdade; desta forma, temos que seus textos irão exprimir a verdade do cronista e, por conseguinte, o que ele pensa sobre um determinado assunto.

Tal reflexão será de làrga relevância na análise de nossa fonte específica, a Crônica de Dom Pedro I. Esta obra, conforme nos afirma Marcella Lopes Guimarães é a fonte narrativa mais importante para a análise deste rei, que foi pai do Mestre de Avis, demonstrando um modo específico de reinar que aqueles tempos demandavam (GUIMARÃES, 2004: p. 85). Apesar das controvérsias quanto a Fernão Lopes ter sido autor também de crônicas de governantes anteriores, indo desde o conde $D$. Henrique até D. Afonso IV, a maioria dos estudiosos lopeanos preferem creditar ao cronista somente a autoria de três obras: a Crónica de D. Pedro I (1357-1367), a Crónica de D. Fernando (1367-1383) e a Crónica de D. João I (1385-1433), esta concluída por Gomes Eanes de Zurara, sucessor de Lopes no cargo de cronista régio.

Como fontes para a composição de suas crônicas, Fernão Lopes dispunha de toda a documentação da Torre do Tombo, além disso, deve ter se deslocado pelo reino a fim de recolher informações importantes, tendo inclusive ouvido testemunhos contemporâneos dos acontecimentos. As crônicas estrangeiras como as de Ayala, já citadas anteriormente, constituem outro importante referencial documental para nosso autor. Marcella Guimarães demonstrou em sua tese de doutoradoa extensa utilização que Fernão Lopes faz dos textos do cronista castelhano. A maior parte dos quarenta e quatro capítulos (acrescidos do prólogo) da Crônica de D. Pedro elaborada pelo cronista português, trata de problemas relacionados à Castela e em seguida, da justiça exercida pelo monarca; contudo, parte menor, mas, importante da obra versa sobre a relação amorosa entre Pedro I e Inês de Castro (GUIMARÃES, 2004: p. 90).

A mesma historiadora ainda postula em seu trabalho que Fernão Lopes constrói um perfil 
monárquico para D. Pedro ímpar em sua crônica, pois dentro da totalidade da obra do cronista este rei é o mais coerente monarca feudal, porque seu poder advém de suas prerrogativas feudais: privilegiou vínculos diretos, era o juiz efetivo e supremo do reino, agradou aos nobres e solicitou o seu dever de conselho. (GUIMARÃES, 2004: p. 87). Aliás, seu caráter justiceiro é um dos fatores que mais sobressaí ao longo de toda a crônica e caracteriza inclusive o epíteto pelo qual o monarca ficou conhecido: o Cru.

Dentro da Crônica de D. Pedro I e da porção que trata sobre o relacionamento entre a dama Inês de Castro (1325-1355) e o rei, encontramos trechos bastante característicos desta representação de monarca que Fernão Lopes realiza. Mas é preciso antes situarmos a personagem Inês de Castro e como seu deu o envolvimento desta com o Cru. Fátima Regina Fernandes ${ }^{14}$ analisa a individualidade que Inês constitui, situando primeiramente o que era ser aia neste período. Desta forma, a historiadora afirma que aias eram filhas das principais linhagens e que tinham sua criação a cargo de outrem, seja em cortes régias ou casas de senhores poderosos. Esta criação poderia Ihes render uma ascensão ou estabelecimento vantajoso, sendo elas filhas legítimas de um nobre ou bastardas. Além disso, a aia tinha duas funções básicas: ser dama de companhia de infantas ou nobres e ama dos filhos da monarquia e desta nobreza. Muitas vezes essa tarefa poderia implicar na mudança definitiva de uma aia de um reino para outro. (FERNANDES, 2005: p. 2). E este é o caso de Inês de Castro, filha bastarda do castelhano Pero Fernández de Castro é criada na casa do nobre João Afonso de Albuquerque. Este nobre é incumbido de conduzir a infanta Constança Manuel ${ }^{15}$ ao reino português, onde esta iria se casar com o ainda Infante Pedro. Desta forma, temos que Inês era aia da futura rainha de Portugal.

Pedro se casa com Constança, mas acaba se apaixonando pela dama que servia à sua esposa. Fátima Fernandes aponta que não há uma data segura do início desta relação ilegítima, mas afirma também que o caso era publicamente tolerado (FERNANDES, 2005: p. 5), sendo comum o envolvimento dos reis com amantes neste período. No entanto, na situação de Pedro e Inês haverá um percalço: a instabilidade interna e externa dos reinos de Portugal e Castela na primeira metade do século XIV, acaba por gerar conseqüências nesta relação. Pedro ao se envolver com Inês, aproximase também dos irmãos desta, notadamente e Álvaro Peres de Castro e Fernando Peres de Castro. Os irmãos Castro envolvem-se numa disputa nobiliárquica contra o rei castelhano Pedro, O Cruel. Álvaro e Fernando teriam incitado o Infante Pedro a ficar com a coroa castelhana caso o monarca deste reino fosse derrotado. Tal influência direta dos castelhanos Castro sobre o infante português preocupou tanto o pai deste, o monarca Afonso IV (1325-1357), quanto outros nobres de linhagens portuguesas importantes, detentoras da privança régia e que temiam perdê-la para os representantes da linhagem castelhana em Portugal. Além disso, muitos estudiosos apontam outro problema que iria se colocar no caminho de Pedro e Inês: o fato de os dois terem tido três filhos de sua relação, a nomear João (nascido por volta de 1352), Beatriz (com nascimento provável em 1354) e Dinis (nascido em 1355). 
Estes filhos ilegítimos constituíam uma preocupação para Afonso IV devido à possibilidade de que houvesse uma disputa entre eles e Fernando, seu neto legítimo, pois o próprio monarca havia tido problemas com irmãos bastardos para assumir o trono de Portugal. Desta forma, e incitado por seus conselheiros Pero Coelho, Álvaro Gonçalves e Diogo Lopes Pacheco, Afonso IV decide que a melhor forma de impedir estes problemas era a morte de Inês, que romperia a ligação de Pedro com os irmãos Castro, afastando a ameaça castelhana que os dois representavam por sua influência junto ao Infante.

A historiografia muito discute a respeito destes possivveis motivos que teriam levado à execução de Inês de Castro, a qual teria sido degolada em Coimbra ainda em janeiro de 1355. Mariana Sales ${ }^{16}$ apresenta a versão de quatro importantes estudiosos portugueses a respeito do assassinato de Inês. Antônio José Saraiva teria creditado a morte da aia a mais um motivo além dos que já citamos, o qual se constituía do fato que Afonso IV condenava as relações adúlteras entre Pedro e Inês e a teria expulsado de Portugal, mas Pedro contrariou a decisão do pai e promoveu o retorno dela à Portugal. Isso teria gerado uma disputa de poder entre Afonso IV e seu filho, o monarca sentindo-se contrariado pode ter tido vontade de se vingar e demonstrar seu poder ao infante, mandando matar sua amante. Em outra linha interpretativa, Oliveira Marques afirmou que Pedro teria sido convertido em uma espécie de joguete nas mãos da aia, que pertencia a uma poderosa família de terratenentes de Castela, e de seus parentes castelhanos também. Afonso IV, como monarca orgulhoso de Portugal não toleraria tal fato, acabando por condenar Inês à morte, dando origem também ao que se tornaria um dos maiores mitos de amor da História Portuguesa. A interpretação de Maria Leonor Machado caminha nesta mesma direção, afirmando que a importância de Inês de Castro reside justamente em sua morte, a qual teria posto fim a uma conjura que punha em risco a independência portuguesa. Mas a própria autora questiona essa ameaça, postulando que a morte de Inês pudesse estar vinculada à vaga desconfiança política que a argumentação histórica muitas vezes tem colocado. Neste sentido, Luís de Sousa Rebelo ressalta que as primeiras crônicas da história portuguesa apresentam relatos de D. Afonso IV e D. Pedro cuidadosamente arquitetados por Fernão Lopes na primeira metade do século XV.Quando o cronista escreveu a Crônica de D. Pedro I na década de 1440, produziu um eclipsamento dos Castro, alternado com a representação deles enquanto ameaça à Portugal, desde a época da morte de Inês; Mas os Castro representavam maior ameaça ao Mestre de Avis do que à Fernando (SALES: 2008, p. 29).

O amor de Pedro e Inês será como observamos acima um tema importante da crônica de Fernão Lopes, o qual estava comprometido com a Dinastia de Avis. Seu relato sobre os acontecimentos relacionados ao caso de Pedro e Inês permaneceu nas interpretações da historiografia e ainda hoje aparece como referência de verossimilhança muito mais forte que a de outros autores que tratam do mesmo assunto. Considerando o peso dessa interpretação, analisaremos alguns aspectos da Crônica de D. Pedro I referentes à construção que o autor faz da personagem Inês de Castro. Primeiramente, há que considerar a quantidade de citações de seu nome durante o texto, indo do capítulo 1 ao último 
(o 44), a aia aparece em oito deles ${ }^{17}$, sendo também a mulher mais citada de toda a obra. A maioria das mulheres que são nomeadas na crônica são ou nobres citadas em trechos relacionados às alianças matrimoniais para manter a estabilidade dos reinos de Portugal e Castela; tal o caso de Dona Isabel, filha de Pedro de Castela, que teve seu casamento planejado com o Infante D. Dinis, filho de D. Pedro de Portugal (LOPES, 1965: 66). Ou são mulheres de outros estratos sociais, que geralmente aparecem vinculadas ao exercimento da justiça do monarca e por isso em questões morais; como no caso de Maria Roussada, a qual teve seu marido morto pelo rei quando este soube que ele havia dormido com ela à força antes do casamento (desconsiderando o fato de os dois já viverem em harmonia e com filhos). (LOPES, 1965: p. 42)

Já Inês aparece como um cașo aparte, relacionada a maioria das vezes aos motivos de sua morte, ao suposto casamento secreto entre Pedro e ela, à vingança do Cru contra os seus assassinos, ao seu caso de amor com o monarca e por fim, o traslado de seu corpo para o mosteiro de Alcobaça, no qual foi feito, a mando do rei, seu rico e ornamentado túmulo, construído juntamente com o que seria de D. Pedro. Ao contrário de outros personagens da crônica que possuem voz ativa, ou até mesmo discursos elaborados pelo autor (estes somente são figuras masculinas), Inês não aparece com nenhuma fala ou exercendo um papel direto em alguma questão ${ }^{18}$, porém, seu papel nos rumos do reinado de Pedro e logo após este é fundamental. Sua figura, assim como a construção do justiceiro, é responsável pela representação de monarca que Fernão Lopes desejava transmitir a respeito de D. Pedro I. Ao lermos a crônica, a impressão que o autor nos passa deste rei é a de um homem empenhado em viver seu amor, e que após a interrupção deste pelo assassinato de Inês, não mede esforços para vingar sua predileta. Em trechos como "Este rei nom quis mais casar depois da morte de Dona enes em seendo Iffante, nem depois que reinou the prouve receber molher, mas ouve amigas com que dormio (...)" (LOPES, 1965: p. 9); percebe-se o valor que o cronista atribui ao sentimento que o monarca tinha por aquela aia.

Outro exemplo muito nítido e que reúne o caráter justiceiro ao amor do monarca por Inês é o da vingança de Pedro contra os conselheiros assassinos de sua amante. Este é o tema do capítulo 30 e 31 da crônica, no qual Fernão Lopes aborda a troca de prisioneiros entre Pedro de Portugal e Pedro de Castela, sendo que o monarca castelhano entrega Pero Coelho e Álvaro Gonçalves ao Cru. É interessante notar neste trecho a reprovação que o autor faz de tal ato, como o cronista tinha liberdade para escrever o que pensava e estava comprometido a escrever fatos verídicos (mas só poderia escrever a partir de sua própria verdade) é natural para ele como homem de seu tempo preocupado com as leis, reprovar um escambo como este, que implicou também numa morte cruel conferida pelo monarca português aos dois conselheiros capturados. Pedro, na narrativa, teria mandado arrancar o coração dos dois, um pelo peito e o outro pelas costas. Fernão Lopes assim cita: "A maneira de sua morte (...) seria mui estranha e crua de comtar" (LOPES, 1965: p. 149). 
Além deste relato da vingança ainda temos outros referentes ao conflito que Pedro gera com seu pai após a morte de Inês, ao grandioso cortejo fúnebre que o infante manda fazer em homenagem à sua amada, entre outras várias. O último capítulo da crônica ("Como foi trellada Dona Enes pera o moesteiro Dalcobaça, e da morte del Rei Dom Pedro") é um exemplo aparte, pois nele observamos toda a reflexão teórica que o autor faz a respeito do sentimento de Pedro por Inês e porque o caso dos dois constituía um amor verdadeiro e real:

"Por que semelhante amor, qual el Rei Dom Pedro ouve a Dona Enes, raramente he achado em alguuma pessoa, porem disserom os antiigos que nenhuum he tam verdadeiramente achado, como aquel cuja morte nom tira da memória o gramde espaço do tempo (...)" (LOPES, 1965: p. 199)

Dom Pedro não esqueceu Inês após a morte desta, ela permaneceu viva em sua memória e por isto o cronista considera o amor dos dois fundamentado na verdade. A descrição que o autor faz de atos do monarca, como a construção do suntuoso túmulo em Alcobaça atua como confirmadora deste fato. Este tema é escolhido para encerrar sua crônica, e nisto, podemos depreender novamente a imagem que o Fernão Lopes quis passar de D. Pedro I: um monarca "cru", mas que teve um profundo amor por uma mulher, um amor em termos jurídicos e religiosos ilegítimo, mas que para este cronista da primeira metade do século XV era um dos únicos amores verdadeiros que ele poderia considerar.

\section{REFERÊNCIAS:}

Fonte:

LOPES, Fernão. Crônica de D. Pedro I. Porto: Livraria Civilização, 1965.

Bibliografia:

AMADO, T. Os pensamentos do cronista Fernão Lopes. eHumanista, vol. 8, p. 133-142, 2007. Disponível em: <http://www.ehumanista.ucsb.edu/volumes/volume_08/index.shtml>. Acesso em: 05/08/2008.

DUBY, G. Eva e os padres. São Paulo: Companhia das Letras, 2001.

FERNANDES, F. R. As potencialidades da função de aia na Baixa Idade Média. Estudios de Historia de España, Buenos Aires, n. 7, p.77-96, 2005.

GIVEN-WILSON, Chris. Chronicles. The Writing of History in Medieval England. London: Hambledon and London, 2004.

GUIMARÃES, M. L. Estudo das representações de monarca nas crônicas de Fernão Lopes (séculos XIV e XV): O espelho do rei: “Decifra-me e te devoro". 275ff. Tese (Doutorado em História) - Setor de Ciências Humanas, Letras e Artes, Universidade Federal do Paraná, Curitiba, 2004. 
OLIVEIRA MARQUES, A. H. Ensaios de historiografia portuguesa. Lisboa: Palas, 1988.

SALES, Mariana. Vínculos políticos luso-castelhanos no século XIV. In: MEGIANI, A. P. T. \& SAMPAIO, J. P. (Orgs.) Inês de Castro: A época e a memória. São Paulo: Alameda, 2008. p. 13-29.

SARAIVA, A. J. História da Cultura em Portugal. Lisboa: Jornal do Foro, 1950. v. 1 